\title{
Atypical IgA-associated vasculitis - case reports
}

\author{
Julia Mirecka' ${ }^{1}$, Małgorzata Stańczyk ${ }^{1,2}$, Marcin Tkaczyk1,3 \\ 'Department of Paediatrics, Immunology, and Nephrology, Polish Mother's Memorial Hospital Research Institute, Lodz, \\ Poland \\ ${ }^{2}$ Department of Paediatrics, Preventive Cardiology and Immunology of Developmental Age, Medical University of Lodz, \\ Poland \\ ${ }^{3}$ Division of Didactics in Paediatrics, Medical University of Lodz, Poland
}

\section{ABSTRACT}

Introduction: IgA-associated vasculitis (IgA vasculitis, IgAV), formerly known as Henoch-Schönlein purpura, is the most common systemic inflammation of the small vessels in children. The disease most often affects the skin, joints, digestive tract and kidneys. It is usually characterised by a mild and self-limiting course and full recovery within a few weeks. The paper presents the cases of patients with severe and complicated IgAV. Case report: In both cases, the kidneys were affected by the disease. The first patient had rare necrotic skin changes and splenic infarction not previously described. The second patient developed hypertension and nephropathy with nephrotic proteinuria.

Conclusions: IgA-associated vasculitis can have a severe course and produce rare complications. Patients may require non-standard individualised management as well as long-term clinical observation to monitor renal function parameters and complications of the treatment.

\section{KEY WORDS:}

vasculitis in children, nephropathy, necrotic skin lesions, splenic infarction.

\section{INTRODUCTION}

IgA-associated vasculitis (IgA vasculitis - IgAV, formerly Henoch-Schönlein purpura - HSP) [1] is the most common systemic inflammation of the small vessels in children. The disease involves deposition of IgA in the vascular walls. It is estimated that the annual incidence of the disease is about 10 cases per 100,000 [2]. IgAV can develop at any age; however, $90 \%$ of patients are children under 10 years of age. The disease usually affects the skin, joints, digestive tract and kidneys. Its aetiology has not been fully understood, although the condition is often preceded by bacterial infection (e.g. with B-haemolytic group A streptococci) or viral infection, antibiotic therapy, or vaccination. HSP is usually a self-limiting disease and requires only symptomatic treatment, with full recovery in a few weeks [2]. The paper presents two cases of patients with HSP. Each of them required individualised actions because the clinical picture was different and the course of the disease was unpredictable.

\section{CASE STUDY 1}

A nine-year-old boy was admitted to the hospital due to a spotty-haemorrhagic rash on the lower limbs and buttocks as well as swelling and pain of the elbow and

\section{ADDRESS FOR CORRESPONDENCE:}

Julia Mirecka, Department of Paediatrics, Immunology, and Nephrology, Polish Mother's Memorial Hospital

Research Institute, 281/289 Rzgowska St., 93-338 Lodz, Poland, ORCID: 0000-0002-3460-4895,

e-mail: julia.mirecka@gmail.com 
knee joints with impaired mobility. The day before, the boy vomited; at admission he was diagnosed with an upper respiratory tract infection. Laboratory tests showed moderately elevated inflammatory markers (leukocytosis $18730 / \mu \mathrm{l}$, CRP $2 \mathrm{mg} / \mathrm{dl}$ [n: $1 \mathrm{mg} / \mathrm{dl}]$ ) with normal plasma coagulogram. IgA-associated vasculitis was diagnosed based on the clinical picture. Antibiotic therapy (amoxicillin with clavulanic acid), probiotic, etamsylate, ibuprofen, rutoside with ascorbic acid, ondansetron, and intravenous infusion were implemented, giving a quick improvement. On the third day, due to the deterioration of the child's clinical condition, systemic steroid therapy (hydrocortisone at a dose of $10 \mathrm{mg} / \mathrm{kg} /$ day) was introduced followed by a relapse of new skin lesions on the face in the form of extensive haemorrhagic papules, followed by peritoneal exudates and extensive soft tissue swelling. On the sixth day of the disease, the patient developed features of nephropathy, including proteinuria and haematuria as well as hypertension and loose, bloody, abundant stools. There were confluent macular eruptions located on the skin of the upper and lower extremities, trunk, face, and ears, and a centrally located, single necrotic lesion on the left cheek and auricle (Fig. 1). The elbows were considerably swollen, painful, and immobile. Due to the lack of treatment effect, a single intravenous immunosuppressive dose of immunoglobulins was administered $(1 \mathrm{~g} / \mathrm{kg})$. The diagnosis of causes of the immune response excluded an infection with Mycoplasma, Yersinia, and Salmonella. Antinuclear (ANA) and anti-neutrophil (ANCA) antibodies were not detected in immunological tests. The concentration of the complement component C3 was slightly reduced. During the hospitalisation, a gradual improvement was observed. The skin lesions largely subsided. On the day of discharge (day 22 of treatment), new, typical macular lesions appeared in the area of the ankle. Other symptoms resolved. From the beginning of hospitalisation, increasing throm-
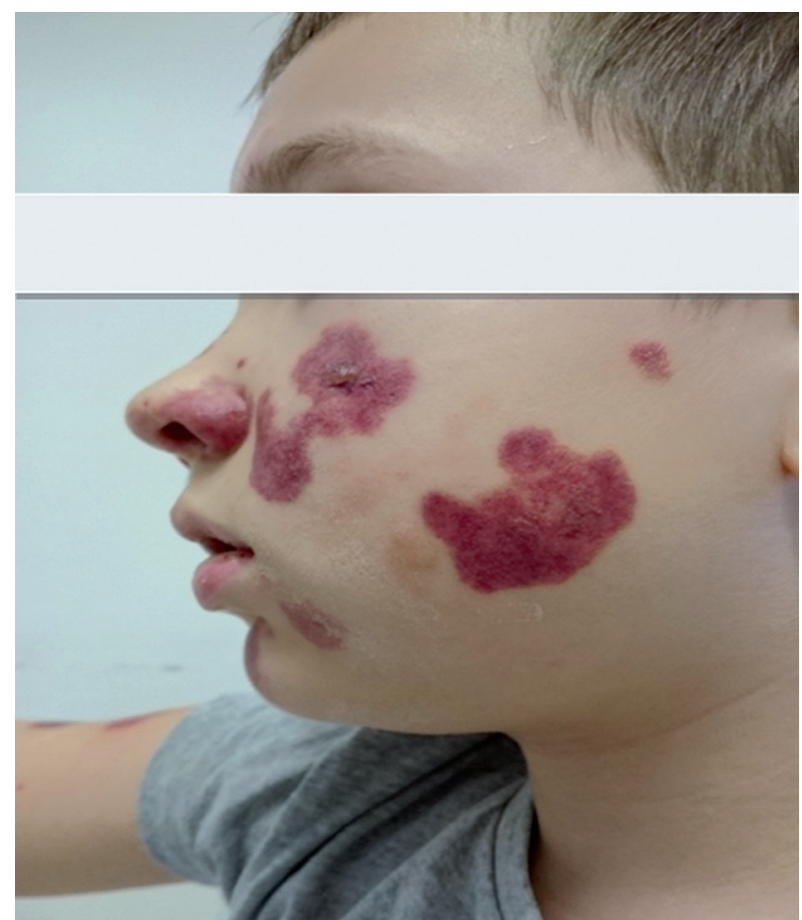

FIGURE 1. Necrotic skin lesions - case 1

bocythaemia (up to a value of $1,025,000 / \mu \mathrm{l}$ ) and a high level of D-dimers $(3920 \mathrm{ng} / \mathrm{ml})$ were observed. Imaging examinations revealed a complication of the disease, i.e. splenic infarction (Fig. 2). Due to the exacerbation of intestinal inflammation, manifested by haemorrhagic diarrhoea, a decision was made to discontinue the treatment with antiplatelet agents. Several months of observation showed no features of splenic infarction. As the course of the disease was severe, the boy was qualified for kidney biopsy, which revealed features of proliferative nephropathy in the course of HSP (group II according to the International Study of Kidney Disease in Children). As a result of the treatment, proteinuria subsided, which justified the gradual reduction of the glucocorticosteroid dose. Three

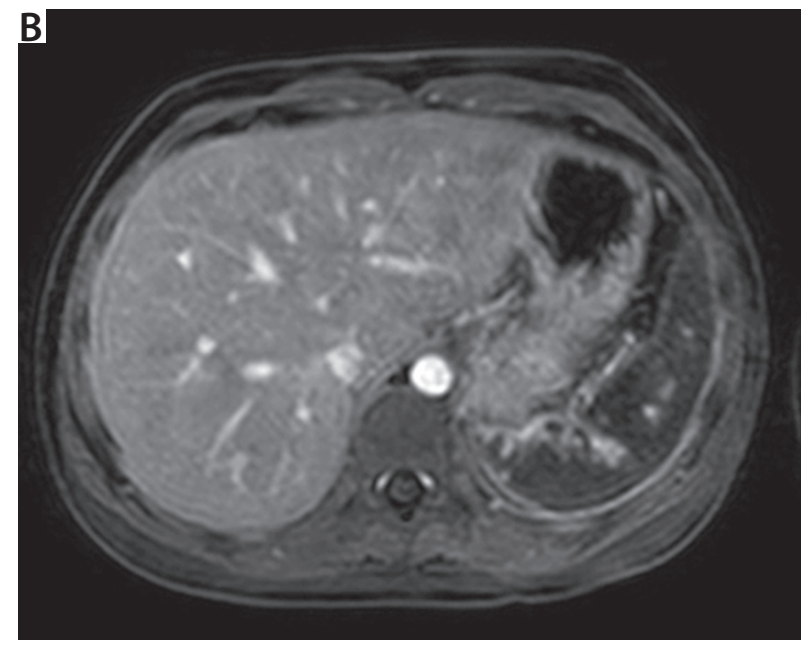

FIGURE 2. Magnetic resonance with contrast imaging of the abdomen - case 1 


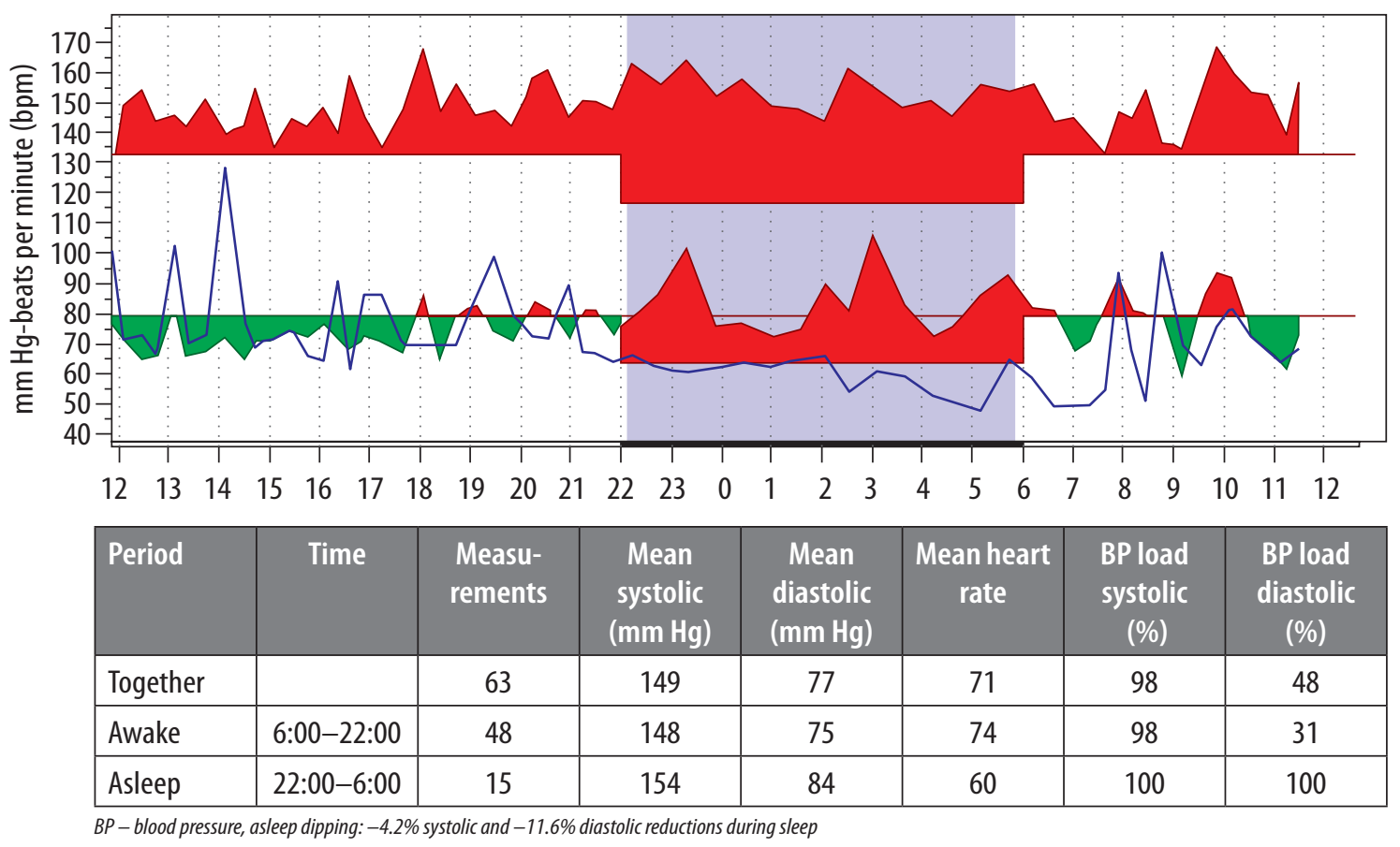

FIGURE 3. 24-hour blood pressure profile - case 2

months after relapse, haematuria, thrombocythaemia, and heterogeneous structure of the spleen parenchyma were observed. After a further three months, the changes in urine subsided completely. No further relapses were reported.

\section{CASE STUDY 2}

A 15-year-old boy was admitted to the hospital due to ecchymotic lesions on the lower limbs. Three days earlier, the boy developed rhinitis which was treated symptomatically. The boy also complained of headache. During hospitalisation, relapses of the skin lesions were reported without other ailments. Laboratory tests showed slight thrombocythaemia (PLT 504000/ $\mu$ l) with normal coagulogram, lipid profile, and high values of $\mathrm{D}$-dimers $(3896 \mathrm{ng} / \mathrm{ml})$. The patient required albumin transfusion due to hypoalbuminaemia $(2.9 \mathrm{~g} / \mathrm{dl})$ accompanied by peritoneal effusion. At week 2 of hospitalisation, nephrotic proteinuria $\left(3.38 \mathrm{~g} / 1.73 \mathrm{~m}^{2} / 24 \mathrm{~h}\right)$ and hypertension grade II were observed (Fig. 3 ). The abovementioned values did not fulfil the criteria of a full-blown nephrotic syndrome. Systemic steroid therapy was applied - three pulses of methylprednisolone (at dose of $750 \mathrm{mg}$ ) followed by prednisone $(2 \mathrm{mg} / \mathrm{kg})$. Two-drug antihypertensive therapy with enalapril (10 mg/day) and amlodipine (10 mg/day) was implemented to achieve good blood pressure control. A kidney biopsy was performed due to nephrotic proteinuria and high hypertension. The histopathological picture corresponded to Henoch-Schönlein nephropathy (group II according to the International Study of Kidney Disease in Children). The diagnosis of causes of the immune response excluded an infection with $\mathrm{CMV}, \mathrm{He}$ licobacter pylori, Mycoplasma pneumoniae, Borrelia, and Parvovirus B19. Antinuclear (ANA) and anti-neutrophil (ANCA) antibodies were not detected. Steroid therapy was continued for a total of 24 weeks, gradually reducing the doses (Table 1). 22 weeks after the first symptoms of the disease, serum glucose was normal as well as renal function based on the level of serum creatinine; no proteinuria was observed. Given the above, it was decided to

TABLE 1. Steroid therapy - case 2

\begin{tabular}{|l|c|c|c|c|c|c|c|c|c|}
\hline $\begin{array}{l}\text { Treatment } \\
\text { duration } \\
\text { (weeks) }\end{array}$ & 4 & 2 & 4 & 2 & 2 & 2 & 2 & 4 & 2 \\
\hline $\begin{array}{l}\text { Prednisone } \\
\text { dose }\end{array}$ & $\begin{array}{c}60 \mathrm{mg} / \\
24 \mathrm{~h}\end{array}$ & $\begin{array}{c}50 \mathrm{mg} / \\
48 \mathrm{~h}\end{array}$ & $\begin{array}{c}40 \mathrm{mg} / \\
46 \mathrm{~h}\end{array}$ & $\begin{array}{c}35 \mathrm{mg} / \\
48 \mathrm{~h}\end{array}$ & $\begin{array}{c}30 \mathrm{mg} / \\
48 \mathrm{~h}\end{array}$ & $\begin{array}{c}25 \mathrm{mg} / \\
48 \mathrm{~h}\end{array}$ & $\begin{array}{c}20 \mathrm{mg} / \\
48 \mathrm{~h}\end{array}$ & $\begin{array}{c}10 \mathrm{mg} / \\
48 \mathrm{~h}\end{array}$ & $\begin{array}{c}5 \mathrm{mg} / \\
48 \mathrm{~h}\end{array}$ \\
\hline Proteinuria & $\begin{array}{c}2.5 \mathrm{~g} / 1.73 \mathrm{~m}^{2} / \\
24 \mathrm{~h}\end{array}$ & $\begin{array}{c}2.5 \mathrm{~g} / 1.73 \mathrm{~m}^{2} / \\
24 \mathrm{~h}\end{array}$ & $\begin{array}{c}2.5 \mathrm{~g} / 1.73 \mathrm{~m}^{2} / \\
24 \mathrm{~h}\end{array}$ & \multicolumn{2}{|c|}{ Missing results } & $\begin{array}{c}2.5 \mathrm{~g} / 1.73 \mathrm{~m}^{2} / \\
24 \mathrm{~h}\end{array}$ & $\begin{array}{c}\text { Free } \\
\text { of proteinuria }\end{array}$ \\
\hline Comments & $\begin{array}{c}\text { Pulses of } \\
\text { methylprednisolone } \\
\text { for 3 days }\end{array}$ & & & & & $\begin{array}{c}\text { Fasting blood } \\
\text { sugar level } \\
125 \mathrm{mg} / \mathrm{dl}\end{array}$ & & \\
\hline
\end{tabular}


end steroid therapy. The patient was under the care of the Nephrological Outpatient Clinic. One and a half years after the first symptoms, the patient still suffered from haematuria with the daily loss of protein of $0.94 \mathrm{~g} / 24 \mathrm{~h}$; therefore, nephroprotective treatment was continued.

\section{DISCUSSION}

IgA-associated vasculitis is the most common vasculitis in children [2]. One hundred per cent of IgAV children have a polymorphic rash, usually in the form of spots, papules, and ecchymoses; in most cases the lesions are located on the distal parts of the lower extremities and buttocks [3]. Other forms of skin lesions may also appear, for example vesicular lesions, erosions, ulcers, necrosis, and gangrene [4]. Approximately $2 \%$ of IgAV patients develop skin complications in the form of vesicular lesions, which may lead to necrosis and scars [5]. Den Boer et al. described two patients suffering from Henoch-Schönlein with vesicular skin lesions. The first patient was initially treated symptomatically, with intravenous prednisone used after nine days of the disease when massive necrotic lesions appeared. The second patient, who received both symptomatic and systemic glucocorticosteroids within 48 hours, developed no necrotic lesions [6]. In the first clinical case, systemic glucocorticosteroids were implemented as early as on day 3 of the disease. It is possible that delaying the use of steroids would lead to a greater severity of necrotic lesions. No consensus has been established on the treatment of isolated skin lesions in IgAV. In case of rare skin changes, such as haemorrhagic vesicular or necrotic lesions, it is reasonable to implement systemic steroid therapy to control inflammation and reduce the extent of necrosis, and thus possible scars on the surface of the skin [6].

The kidneys are involved in approximately $20-60 \%$ of patients with HSP [7]. Haematuria is the most common symptom, with approximately $7 \%$ of patients developing nephrotic or nephritic syndrome [2].

Although $85 \%$ of patients with IgAV will develop the first signs of involvement of the kidneys within four weeks of diagnosis, outpatient care should be exercised because features of kidney damage may become visible up to six months after the onset of the disease [8]. Our patients developed features of involvement of the kidneys earlier. Even though in both cases the renal filtration function did not worsen after the resolution of acute symptoms, in the second case, haematuria and proteinuria persisted; however, chronic renal failure did not occur. According to the systematic review of 2005, which focused on the risk of renal complications in patients with HSP, the possibility of long-term renal failure in patients with isolated proteinuria or haematuria is only $1.6 \%$, but this risk is significantly higher $(19.6 \%)$ in patients with nephrotic or nephritic syndrome (2.5 times higher in females) [8]. It is difficult to predict the duration of renal failure or urine changes in individual patients. The severity of histological changes correlates with the long-term involvement of the kidneys, and therefore in more severe cases renal biopsy is recommended [9].

According to KDIGO 2012 (Kidney Disease Improving Global Outcomes), patients with proteinuria $>1 \mathrm{~g} /$ day/ $1.73 \mathrm{~m}^{2}$ and GFR $>50 \mathrm{ml} / \mathrm{min} / 1.73 \mathrm{~m}^{2}$, in addition to ACE-I, should receive steroid therapy for six months. Although there is no evidence for the validity of using ACE-I and steroids in children with glomerulonephritis of the HSP aetiology, it has been shown that in IgA nephropathy such a treatment reduces proteinuria and allows maintenance of normal GFR [2].

The latest recommendations on the diagnosis and treatment of IgA-associated vasculitis were published in Rheumatology in 2019. The guidelines emphasised the importance of the prevention of permanent kidney damage by monitoring blood pressure and renal function based on eGFR, as well as by performing urine analysis for at least 6-12 months. Increasing evidence indicating a beneficial effect of renin-angiotensin blockade in patients with proteinuria prompted an expert panel to recommend the use of ACE-I in patients with IgAV and proteinuria persisting for more than three months, despite receiving immunosuppressive therapy to prevent glomerular damage. It was pointed out that there are no indications for glucocorticoid administration in the prevention of kidney damage in IgAV [10]. Should the need to perform a biopsy arise, it would be better to assess the histopathology of the kidneys prior to immunosuppressive therapy because the treatment may blur the actual state of the glomeruli.

Splenic infarction observed in the first patient is noteworthy. To date, such a complication of HSP has not been described in the literature. In the group of vasculitis, this complication was reported in patients with Kawasaki disease [11]. Because of very intense intestinal inflammation manifested by severe haemorrhagic diarrhoea, a decision was made not to administer antiplatelet drugs. Because there are no indications for antiplatelet therapy in IgAV, the management leaves room for discussions. We can consider whether the administration of antiplatelet agents would prevent splenic infarction; however, there is uncertainty about the safety of such management in relation to haemorrhagic complications. Over several months of follow-up, the platelet count normalised and no complications of splenic infarction were observed, indicating the low clinical significance of this complication.

The cases described in our study confirm that IgAV/ HSP may have an atypical course and pose a challenge for doctors to select appropriate therapy.

\section{CONCLUSIONS}

There is no single treatment regimen for IgA-associated vasculitis. To varying degrees, the disease affects different systems and requires individualised treatment. 
Although in most cases symptomatic and nephroprotective treatment is sufficient, some patients need immunosuppressive therapy.

\section{DISCLOSURE}

The authors declare no conflict of interest.

\section{REFERENCES}

1. Wiatr E, Gawryluk D. [Primary systemic ANCA-associated vasculitis--recommendations concerning diagnosis and treatment]. Pneumonol Alergol Pol 2013; 81: 479-491.

2. KDIGO Clinical Practice Guidelines for Glomerulonephritis. Kidney Int Suppl 2012; 2: 218-220.

3. Paller A, M Mancini A. Hurwitz Clinical Pediatric Dermatology. A Textbook of Skin Disorders of Childhood and Adolescence. 5th ed. Elsevier; 2016: 495-498.

4. Garland JS, Chusid MJ. Henoch-Schönlein purpura: association with unusual vesicular lesions. Wis Med J 1985; 84: 21-23.

5. Saulsbury FT. Henoch-Schonlein purpura in children. Report of 100 patients and review of the literature. Medicine (Baltimore) 1999; 78: 395-409.

6. Den Boer SL, Pasmans S, Wulffraat NM, et al. Bullous lesions in Henoch Schonlein Purpura as indication to start systemic prednisone. Acta Paediatr 2010; 99: 781-783.

7. McCarthy HJ, Tizard EJ. Clinical practice: Diagnosis and management of Henoch-Schonlein purpura. Eur J Pediatr 2010; 169: 643-650.

8. Narchi H. Risk of long term renal impairment and duration of follow up recommended for Henoch-Schonlein purpura with normal or minimal urinary findings: a systematic review. Arch Dis Child 2005; 90: 916-920.

9. Pohl M. Henoch-Schonlein purpura nephritis. Pediatr Nephrol 2015; 30: 245-252.

10. Ozen S, Marks SD, Brogan P, et al. European consensus-based recommendations for diagnosis and treatment of immunoglobulin A vasculitis-the SHARE initiative. Rheumatology (Oxford) 2019; 58: 1607-1616.

11. Huong DL, Gatfosse M, Papo T, et al. Symptomatic splenic infarction complicating adult Kawasaki disease. Br J Rheumatol 1995; 34: 579-580. 